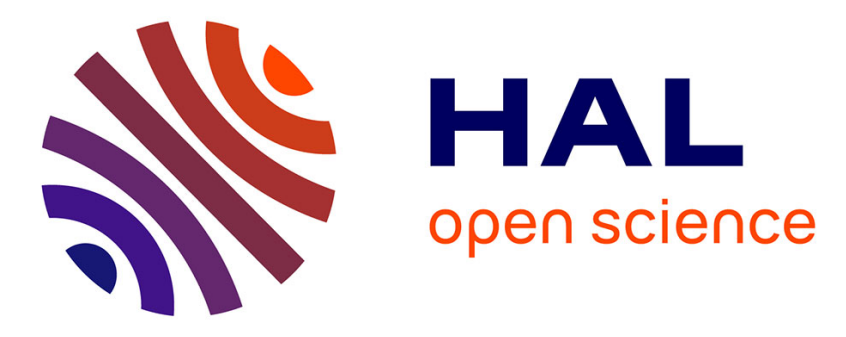

\title{
Layered Structures HTSC/Ferroelectric, Prepared by Sputtering
}

\author{
K. Grigorov, R. Chakalov, A. Spasov, A. Benhocine, D. Bouchier, S. \\ Karmanenko, A. Dedyk
}

\section{- To cite this version:}

K. Grigorov, R. Chakalov, A. Spasov, A. Benhocine, D. Bouchier, et al.. Layered Structures HTSC/Ferroelectric, Prepared by Sputtering. Journal de Physique IV Proceedings, 1996, 06 (C3), pp.C3-301-C3-307. 10.1051/jp4:1996346 . jpa-00254264

\section{HAL Id: jpa-00254264 https://hal.science/jpa-00254264}

Submitted on 1 Jan 1996

HAL is a multi-disciplinary open access archive for the deposit and dissemination of scientific research documents, whether they are published or not. The documents may come from teaching and research institutions in France or abroad, or from public or private research centers.
L'archive ouverte pluridisciplinaire HAL, est destinée au dépôt et à la diffusion de documents scientifiques de niveau recherche, publiés ou non, émanant des établissements d'enseignement et de recherche français ou étrangers, des laboratoires publics ou privés. 


\title{
Layered Structures HTSC/Ferroelectric, Prepared by Sputtering
}

\author{
K.G. Grigorov, R.A. Chakalov, A. Spasov, A. Benhocine*, D. Bouchier*, S.F. Karmanenko** and \\ A.I. Dedyk** \\ Institute of Electronics, Bulgarian Academy of Sciences, 72 Tzarigradsko Chaussee, 1784 Sofia, Bulgaria \\ * Institut d'Électronique Fondamentale, CNRS URA, Bat. 220, Université Paris-Sud, 91405 Orsay Cedex, \\ France \\ ** Sankt-Petersburg Electrotechnical University, 5 Prof. Popov Str., 197376 Sankt-Petersburg, Russia
}

\begin{abstract}
We have investigated some formation features of thin film structures PZT / YBCO and YBCO / BSTO. PZT films have been synthesized by reactive ion beam sputtering of a multi-elemental metal target at room temperature and "ex-situ" annealing at $700-750^{\circ} \mathrm{C}$. BSTO and YBCO films have been deposited "in-situ" by magnetron sputtering of stoichiometric ceramic targets in an $\mathrm{Ar}+50 \% \mathrm{O}_{2}$ gas mixture (pure oxygen for BSTO) at temperature of $700^{\circ} \mathrm{C}$. Si $(100)$ buffered with TiN to prevent the diffusion in YBCO has been used as a substrate in the case PZT / YBCO. The layers YBCO / BSTO have been deposited on $\mathrm{MgO}(100)$. The substrates have been chosen according to prospective applications of $\mathrm{PZT}$ / YBCO as non-volatile memory cells integrated with existing CMOS transistor circuitry, and of YBCO / BSTO as voltage-tunable microwave devices. Films with composition $\mathrm{Pb}\left(\mathrm{Zr}_{0.44} \mathrm{Ti}_{0.56}\right) \mathrm{O}_{3}$ have been obtained by sputtering of a target with a ratio of $13: 36: 51$ for $\mathrm{Pb}, \mathrm{Sr}$ and $\mathrm{Ti}$, respectively. The measured dielectric constant at $1 \mathrm{MHz}$ in the structures Au / PZT / YBCO / TiN / Si has been 540 and the remnant polarization and coercive field values have been $5.4 \mu \mathrm{C} / \mathrm{cm}^{2}$ and $25 \mathrm{kV} / \mathrm{cm}$, respectively. Planar capacitors with a dielectric of BSTO thin film and YBCO electrodes have been produced and investigated as voltage-controlled devices at $1 \mathrm{MHz}$. A controllability of $\varepsilon(0 \mathrm{~V}) / \varepsilon(50 \mathrm{~V})=1.6$ has been demonstrated at $77 \mathrm{~K}$. The dielectric hysteresis has been compared in capacitors with YBCO electrodes and with metal ones. It has been shown that the boundary phenomena at the interface of the epitaxially grown layers differ from that in the ferroelectric/metal structures and the hysteresis effect diminishes significantly.
\end{abstract}

\section{INTRODUCTION}

Layered structures with ferroelectric and high-temperature superconducting (HTSC) thin films have attracted much attention, firstly, due to their potential applications as non-volatile memories [1] or voltage-tunable microwave devices [2], and, secondly, because of the possibility for epitaxial growth initiated by the similar crystal structure and close lattice matching of these perovskite-type oxide materials. Laser ablation has been shown to be an effective method for preparation of such structures but the deposition area is restricted by the dimensions of the ablated plume. Another promising technique which has been recently successfully employed in producing high-quality HTSC thin films, is sputtering.

We have investigated some formation features of thin film structures $\mathrm{Pb}\left(\mathrm{Zr}_{\mathrm{x}} \mathrm{Ti}_{1-\mathrm{x}}\right) \mathrm{O}_{3} / \mathrm{YBa}_{2} \mathrm{Cu}_{3} \mathrm{O}_{7-\delta}$ ( $\mathrm{PZT} / \mathrm{YBCO}$ ) and $\mathrm{YBa}_{2} \mathrm{Cu}_{3} \mathrm{O}_{7-\delta} /\left(\mathrm{Ba}_{\mathrm{x}} \mathrm{Sr}_{1-\mathrm{x}}\right) \mathrm{TiO}_{3}$ (YBCO / BSTO). 


\section{STRUCTURES PZT / YBCO}

PZT films were synthesised by reactive ion beam sputtering of a multi-elemental target at room temperature and ex-situ annealed at $700-750^{\circ} \mathrm{C}$. Si $(100)$ buffered with TiN to prevent the diffusion of YBCO [3] was used as a substrate according to the prospective application of PZT/YBCO as non-volatile memory cells integrated with existing CMOS transistor circuitry. YBCO films of $800 \AA$ thickness and 0.9 $\mathrm{m} \Omega . \mathrm{cm}^{-1}$ room temperature resistivity were deposited by r.f. magnetron sputtering.

In order to obtain the desired stoichiometry, corresponding to the ferroelectric state for the PZT ceramic, some formation features like effect of the oxygen partial pressure, target composition, material transport phenomenon and the influence of the substrate temperature were investigated. Three PZT targets denoted hereafter as I,II, and III with (23:38:39), (20:34:46) and (13:36:51) (Pb:Zr:Ti) percent surface areas respectively, were sputtered with $2 \mathrm{keV} \mathrm{Ar}$ ions at $45^{\circ}$. The substrate-target distance and the ion current density were $4 \mathrm{~cm}$ and $0.2 \mathrm{~mA} . \mathrm{cm}^{-1}$ respectively. More details on the experimental conditions can be found in [4]. The estimated elemental concentrations of the deposited materials were determined by gravimetry, EDX and RBS.

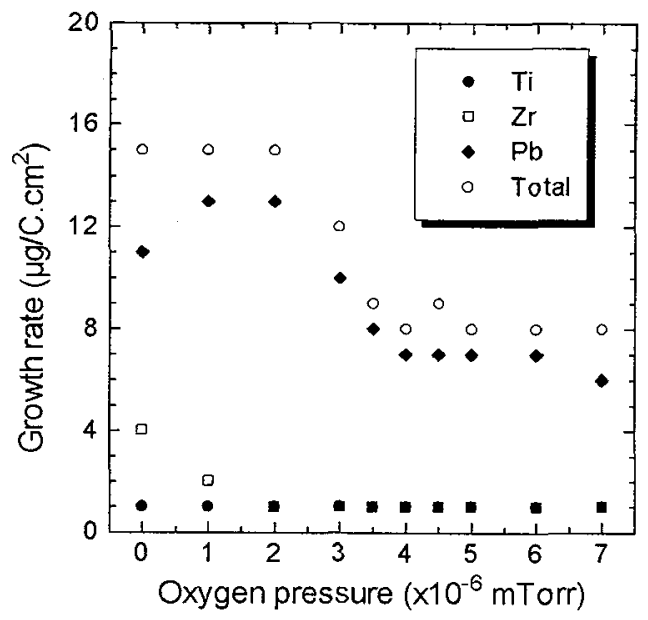

Fig. 1. Pb sputtering vs. oxygen partial presure

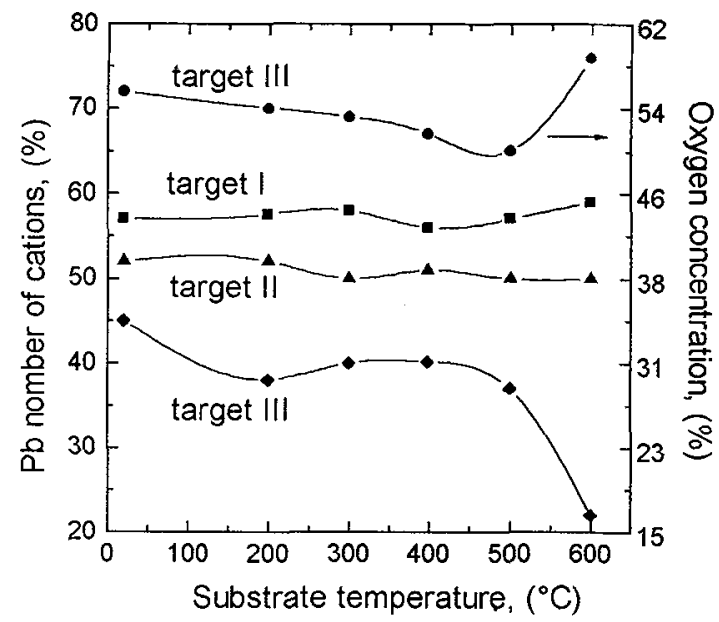

Fig. 2. Lead and oxygen film concentration vs. substrate temperature

In Fig. 1 a strong decrease of the lead content is observed for an oxygen pressure of 3.5.10-6 Torr. This threshold value is much lower for $\mathrm{Zr}$ and $\mathrm{Ti}$ - about $1.5 .10^{-6}$ Torr. This considerable decrease of the sputtering yield is associated with the oxidation of the surface of the target. To confirm the latter the Auger KLL peaks of oxygen and $\mathrm{N}_{6} \mathrm{O}_{45} \mathrm{O}_{45}$ of lead were recorded at different oxygen pressures under 500 $\mathrm{eV} \mathrm{Ar}{ }^{+}$bombardment. For oxygen pressures lower than $4.10^{-6}$ Torr, the peak from the adsorbed oxygen is shifted, but no signal of the oxidised lead is observed. At $4.10^{-6}$ Torr $\mathrm{O}_{2}$ pressure, the surface of the lead passed from the metallic to the oxidised state and a chemical shift of about $3 \mathrm{eV}$ confirms the formation of $\mathrm{PbO}$. Because of the total disappearence of the metal signal, the thickness of this layer is greater than three monolayers $(1 \mathrm{~nm})$. 


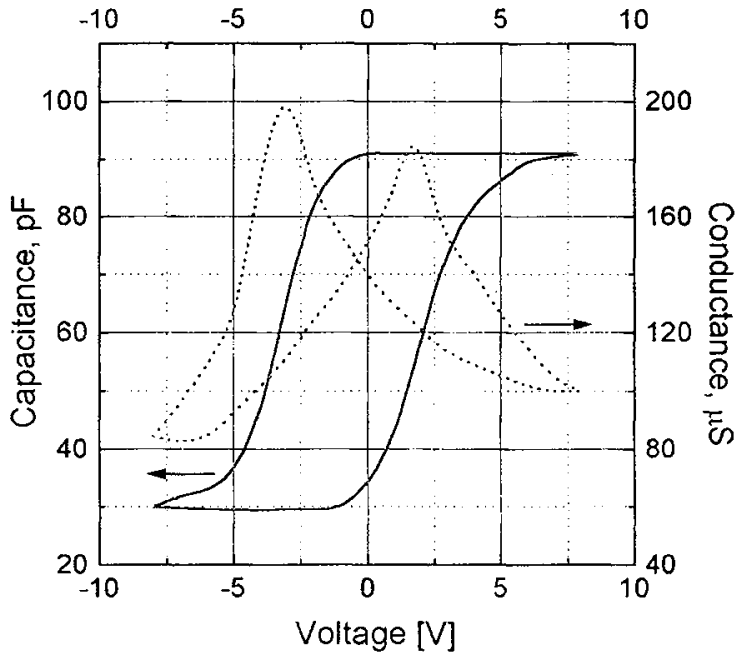

Fig. 3. Au/PZT/YBCO/TiN/SI voltage-capacity characteristic
On the other hand the role of the substrate temperature was found to be useful to understand how the oxygen concentration in the film is related to the lead concentration in the target. In Fig. 2 the variation of the lead concentration in the film is shown when the substrate temperature varies from 20 to $600^{\circ} \mathrm{C}$. An important losse of lead (without oxygen concentration change) at higher temperature is characteristic when the leadpoor target III is sputtered. The latter suggests that this reduction of lead concentration in the film is due to its evaporating $\mathrm{as} \mathrm{Pb}$ or $\mathrm{PbO}$ because of their very identical vapour tension in this temperature range. A light deficit of oxygen (Fig.2) can explain this phenomenon. Two possible mechanisms of oxygen incorporation of the PZT films are contemplated: (i) direct molecular oxygen adsorption and (ii) incorporation of oxygen atoms sputtered from the target - process stimulated by the

backscattered ions bombardment. The oxides formed on the $\mathrm{Zr}$ and $\mathrm{Ti}$ surfaces are most probably $\mathrm{ZrO}_{2}$ and $\mathrm{TiO}_{2}$, more rich in oxygen than $\mathrm{PbO}$. Therefore the relative increase of $\mathrm{Pb}$ concentration of the target surface cannot lead to an important variation of the sputtered oxygen flux, but it can generate an important flux of backscattered ions. In Table 1 the backscattered ion yields from pure and oxidised target are presented, estimated using the code TRIM [5]. In this context, the mean energy of the backscattered ions for $\mathrm{Pb}, \mathrm{Zr}$, and $\mathrm{Ti}$ targets is $0.75,0.45$, and $0.24 \mathrm{keV}$ respectively for ion incident of $2 \mathrm{keV}$. Consequently the effect of ion-induced stimulated adsorbtion of molecular oxygen from the growing PZT film is closely related to the target composition which could explain the significant losse of lead when target III is sputtered. The PZT films of $400 \mathrm{~nm}$ thickness were deposited at room temperature from target $\mathrm{II}\left(\mathrm{Pb}_{1.2} \mathrm{Zr}\right.$ $\left.0.44 \mathrm{Ti}_{0.56}\right)$ at $6.10^{-6}$ Torr oxygen pressure. The $\mathrm{Si} / \mathrm{TiN} / \mathrm{YBCO} / \mathrm{PZT}$ structures obtained have been annealed for 1 hour at 700 and $750^{\circ} \mathrm{C}$ in flowing oxygen at atmospheric pressure. The presence of perovskite phase was confirmed by X-ray diffraction [6] where peaks (00n) for PZT were registered together with (200) and (002) rays for $\mathrm{PbO}$. On the other hand the absence of signal from YBCO substrate proves its poor cristalinity and points towards the formation of other phases at the PZT/YBCO interface. The measured dielectric constant at $1 \mathrm{MHz}$ in the SI/TiN/YBCO/PZT/Au structures was $\varepsilon \approx 540$ and the remnant polarisation and coercive field were $5.4 \mu \mathrm{C} . \mathrm{cm}^{-2}$ and $25 \mathrm{kV} / \mathrm{cm}$, respectively (Fig.3). This polarisation value is less than that of bulk ceramics, but is comparable to those reported for thin PZT films.

\begin{tabular}{|c|c|c|c|}
\hline \multirow[t]{2}{*}{ pure metal } & $\mathrm{Pb}$ & $\mathrm{Zr}$ & $\mathrm{Ti}$ \\
\hline & 0.32 & 0.2 & 0.17 \\
\hline \multirow[t]{2}{*}{$1 \mathrm{~nm}$ oxyde } & $\mathrm{PbO}$ & $\mathrm{ZrO}_{2}$ & $\mathrm{TiO}_{2}$ \\
\hline & 0.3 & 0.18 & 0.007 \\
\hline
\end{tabular}

Table 1. Backscattered ion yields from pure and oxydised target estimated using the code TRIM 


\section{STRUCTURES YBCO / BSTO}

The voltage-tunable microwave devices are based on the properties of ferroelectrics. The possibility to change their dielectric constant $\varepsilon$ by application of electric field provides opportunities a number of unique microwave devices to be developed: phase shifters with voltage tuning of the phase, resonators with voltage tuning of the resonant frequency, delay lines with voltage control of the phase velocity, etc. The proper operation of such devices requires low noise, low losses and low consumption which may be realized by employing HTSC thin films.

From the point of view of the microwave device designer the most important characteristics of the ferroelectrics are: a) controllability by the electric field, expressed as $n=\varepsilon_{\max } / \varepsilon_{\min } ; b$ ) the dielectric losses, presented by $\tan \delta$; and $c$ ) the dependence of $\varepsilon$ on the temperature. The use of the ferroelectrics at microwaves differs from their low-frequency applications in two important features. First, the value of the dielectric losses $\tan \delta$ is high in the ferroelectric state, i.e. bellow the Curie temperature $T_{c}{ }_{c}$, and decreases for the so-called paraphase at $T>T_{c}{ }^{f}$. A reverse behavior is valid for the controllability since it ensues from the non-linearity. Consequently, the ferroelectrics could be employed at microwaves only in a comparatively narrow temperature range where the material is characterized by low $\tan \delta$ and a high value of the controllability. These temperatures correspond to the paraelectric phase and can be defined approximately as $T_{c}^{f}+50 \mathrm{~K}[7]$. At the boiling nitrogen temperature $(77 \mathrm{~K})$ these conditions are satisfied for the solid solution $\mathrm{Ba}_{x} \mathrm{Sr}_{1-\mathrm{x}} \mathrm{TiO}_{3}$ if $\mathrm{x}<0.2$ (the different values of $\mathrm{x}$ provide different values of the phase transition temperature $\left.\mathrm{T}_{c}^{\mathrm{f}}[7]\right)$.

The second feature concerns the hysteresis of the dependence of the dielectric constant on the electric field $\varepsilon(E)$. At low frequencies this hysteresis is the basis of many applications, but it plays a negative role in the microwave voltage-tunable devices since it results in an ambiguity of the function $\varepsilon(E)$ and, therefore, in an infeasible electric field control. That is why the ferroelectrics destined for microwave applications have to posses non-hysteretical dependence $\varepsilon(E)$. The understanding that the hysteresis is due to the remnant polarization, is widely adopted. As it was mentioned above, the ferroelectrics are employed at microwaves in the temperature range where they are in paraelectric state. It means that no hysteresis have to be observed. Notwithstanding, the ambiguous properties are commonly registered in microwave elements based on ferroelectrics and containing metal electrodes. It is ascribed to the phenomena taking place at the interface ferroelectric / metal: the abrupt change of the crystal lattice type and the appearance of a charge layer near the boundary owing to the different electron work functions [8]. This enables to suppose that the boundary phenomena will be changed if the normal metal as electrode material is replaced by a high- $T_{c}$ superconductor.

The creation and investigation of capacitors with ferroelectric and electrodes of HTSC thin films are the initial steps of the development of voltage-tunable devices. In a previous work [9] we reported the results of the fabrication and study of bulk and trilayer capacitor structures. Now the characteristics of planar capacitors formed in YBCO / BSTO double layers will be considered.

An estimation of the dimensions in such devices was made early [7]. It was shown that a noticeable value of the controllability could be expected if the gap between the YBCO electrodes on the top of a BSTO ferroelectric layer deposited on a $\mathrm{MgO}$ substrate is in the order of $2 \mu \mathrm{m}$. To obtain a capacity of $1 \mathrm{pF}$, the length of this gap must be about $1000 \mu \mathrm{m}$.

Firstly, thin BSTO films were deposited on $\mathrm{MgO}(100)$ single crystal substrates by $\mathrm{RF}$ reactive sputtering. Details on the optimization of the deposition parameters are given elsewhere [10], shortly, a 3" stoichiometric target of BSTO prepared by the standard ceramic technology was sputtered in $100 \mathrm{~Pa}$ pure oxygen by an applied RF $(13.56 \mathrm{MHz})$ power with a density of $10 \mathrm{~W} / \mathrm{cm}^{2}$. A quasi-closed condensation cell (made of quarz) was employed to maintain constant conditions in the gas phase. The substrates were mounted very close to the target at a distance of $6 \mathrm{~mm}$ and kept at $720^{\circ} \mathrm{C}$ during deposition. Under these conditions the BSTO deposition rate was $2-3 \mathrm{~nm} / \mathrm{min}$ and BSTO films with thickness of $200 \mathrm{~nm}$ were produced.

YBCO films were deposited on the top of BSTO / MgO samples by magnetron sputtering of a 2" stoichiometric ceramic target in an $\mathrm{Ar}+50 \% \mathrm{O}_{2}$ gas mixture at a substrate temperature of $700^{\circ} \mathrm{C}$. Both 
RF (13.56 MHz) and DC voltage sources were successfully used and the applied power density was about $5 \mathrm{~W} / \mathrm{cm}^{2}$. $\mathrm{T}_{\mathrm{c}}$ values of $88-90 \mathrm{~K}$ were measured for the YBCO films deposited at relatively high total gas pressure $>20 \mathrm{~Pa}$ when the crucial role of growing film bombardment by energetic plasma particles was canceled by the thermalization of the sputtered atoms. "In-situ" deposition included. also filling the chamber with $1 \mathrm{~atm}$ oxygen immediately after the discharge switching off and slow cooling down to room temperature with a rate of $20^{\circ} \mathrm{C} / \mathrm{min}$. Under these conditions the YBCO deposition rate was less than $1 \mathrm{~nm} / \mathrm{min}$ and the produced YBCO films had thickness of $100 \mathrm{~nm}$.

The YBCO/BSTO thin films were investigated by $\mathrm{Cu} \mathrm{K} \alpha$ X-ray diffraction. A typical X-ray diffractogram is shown in Fig.3. Strong peaks (n00) were registered for BSTO and (00n) for YBCO which evidenced for the high-quality of the crystal structure and for the highly oriented growth of the both layers. The c-axis of the YBCO films was perpendicular to the substrate surface (c-oriented films) and no presence of a-oriented particles was detected. Another proof of the crystal structure perfectness was the low value of the full width at half maximum (FWHM) of the YBCO $(005)$ peak: $0.2^{\circ}$.

Before the lithographic operations the structures YBCO / BSTO / MgO were covered by a thin ( $30 \mathrm{~nm}$ ) thermally evaporated gold film. Electrical contact areas were fabricated from this film finally but it played an important role in preventing any interaction between the photoresist and the $\mathrm{YBCO}$. The pattern in the resist was formed by a standard contact photolithographic procedure. Then the gaps in the YBCO thin films were etched by Ar ion-beam milling. A value of the etching rate of $5 \mathrm{~nm} / \mathrm{min}$ was preliminary determined for ion energy of $500 \mathrm{eV}$ and current density of $0.2 \mathrm{~mA} / \mathrm{cm}^{2}$. The sample holder was water cooled to avoid overheating.

Voltage-capacitance characteristics were measured by a standard RLC bridge device at temperatures $\mathrm{T}=77$ and $300 \mathrm{~K}$. The RF (1 MHz) voltage in the scheme was of constant amplitude $(0.1 \mathrm{~V})$ and a DC driving voltage was applied in the range $-80 \mathrm{~V} \ldots+80 \mathrm{~V}$. Fig. 4 shows a typical voltage-capacitance characteristic of a planar $\mathrm{YBCO} / \mathrm{BSTO} / \mathrm{MgO}$ capacitor. The initial capacitance $\mathrm{C}=1.17 \mathrm{pF}$ at $\mathrm{T}=77 \mathrm{~K}$ corresponds to dielectric constant value $\varepsilon \sim 870$. At room temperature $\mathrm{C}=0.98 \mathrm{pF}$ and $\varepsilon \sim 680$. The

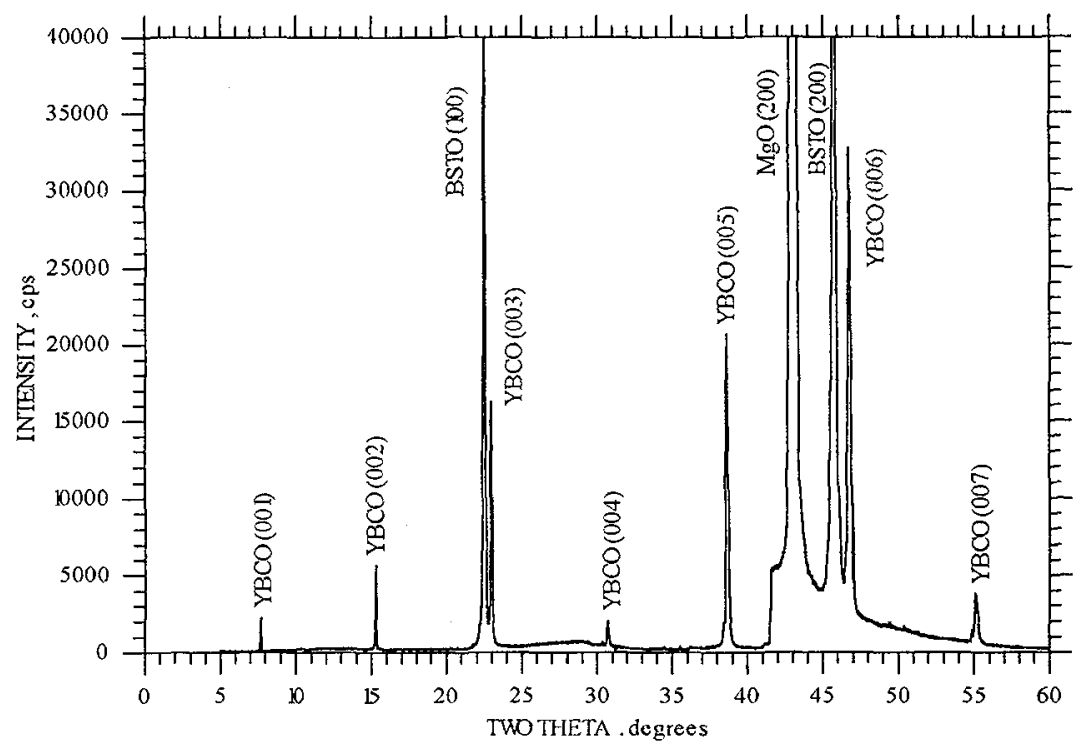

Fig. 4 X-ray diffractogram of a YBCO / BSTO / MgO double layer structure. 


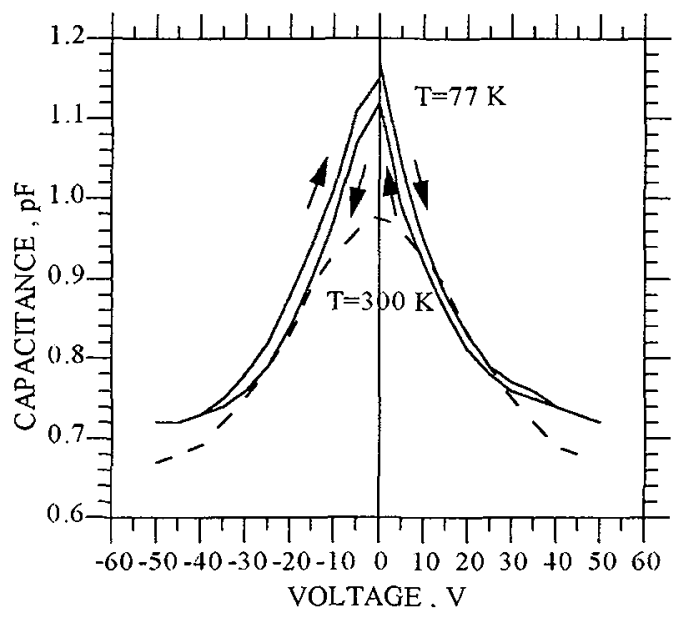

Fig.5. Voltage-capacitance characteristic of a $\mathrm{YBCO} / \mathrm{BSTO} / \mathrm{MgO}$ planar capacitor

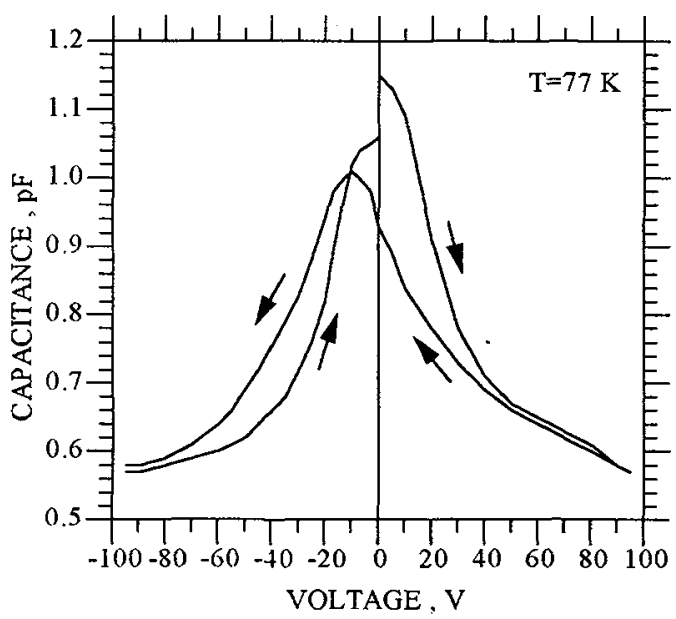

Fig.6. Voltage-capacitance characteristic of a $\mathrm{Ni} / \mathrm{BSTO} / \mathrm{MgO}$ planar capacitor

dielectric hysteresis was evaluated by a parameter $\xi=[C(0)-C(V)] / C(V)$. After the first action of the driving voltage its value was about $5 \%$. The dielectric loss tangent was obtained simultaneously with the capacitance measurements and it was estimated to be $\tan \delta=0.04$ at $77 \mathrm{~K}$. The controllability value $\mathrm{n}$ was evaluated as 1.6 at $50 \mathrm{~V}$ applied voltage (electric field $\mathrm{E} \sim 10 \mathrm{~V} / \mathrm{m}$ ) and $\mathrm{T}=77 \mathrm{~K}$. A rather low leakage current in the structures measured pointed out to the absence of "short circuits" between planar capacitor electrodes and the fact that BSTO surface was not considerably damaged at different stages of capacitor structure patterning.

The observation of a small dielectric hysteresis and the significant value of $\tan \delta$ could be explained if the BSTO film at $77 \mathrm{~K}$ is considered to be in a ferroelectric state far from the Curie point. This assumption could be related to a possible higher value of $\mathrm{Ba}$ in the solid solution $\mathrm{Ba}_{\mathrm{x}} \mathrm{Sr}_{1-\mathrm{x}} \mathrm{TiO}_{3}$ (the exact composition of the films was not investigated in this study).

Furthermore it was important to compare the hysteresis effect in planar ferroelectric capacitors supplied by different kind of electrodes - superconductor and normal metal. We have measured the analogous structures differed by electrode material only. Nickel thin films were thermally evaporated on $\mathrm{BSTO} / \mathrm{MgO}$ at $\mathrm{T}_{s} \sim 150^{\circ} \mathrm{C}$ and capacitors with the same pattern as $\mathrm{YBCO} / \mathrm{BSTO} / \mathrm{MgO}$ were fabricated.

A voltage-capacitance characteristic of a planar $\mathrm{Ni} / \mathrm{BSTO} / \mathrm{MgO}$ structure at $77 \mathrm{~K}$ is shown in fig.5. As one can see the sign of the dielectric hysteresis parameter for both kinds of capacitors was negative, i.e. the capacitance decreased after DC voltage applying cycle. A "negative" hysteresis evidences for a prevalent charge carrier injection from electrodes into the ferroelectric and for space charge layer formation at the interface. But it is important to note that hysteresis parameter value of $\mathrm{Ni} / \mathrm{BSTO} \mathrm{MgO}$ capacitors was 3-5 times higher than the $\mathrm{YBCO} / \mathrm{BSTO} / \mathrm{MgO}$ one. Therefore, a conclusion can be drawn that the charge carrier injection in the structures with metal electrodes was essentially higher as compared to the epitaxially grown double layers of perovskite-type materials. 


\section{CONCLUSIONS}

Layered structures with ferroelectric (PZT, YBCO) and HTSC (YBCO) thin films were successfully prepared by sputtering and basic formation features were investigated. The benefit of the close lattice matching of these perovskite-type materials was confirmed. The ratio of $\mathrm{Pb}, \mathrm{Zr}$ and $\mathrm{Ti}$ surface areas in a multielemental target was determined aiming PZT films with composition $\mathrm{Pb}\left(\mathrm{Zr}_{0.44} \mathrm{Ti}_{0.56}\right) \mathrm{O}_{3}$ to be obtained by reactive ion-beam sputtering in oxygen. The values of the deposited films dielectric parameters are suitable for application in non-volatile memories. Highly-oriented heteroepitaxial double layer structures of YBCO / BSTO on MgO (100) substrates were obtained "in-situ" by magnetron sputtering of stoichiometric ceramic targets. Planar capacitors were produced and investigated as voltage-controiled devices at $1 \mathrm{MHz}$. A controllability of $\varepsilon(0 \mathrm{~V}) / \varepsilon(50 \mathrm{~V})=1.6$ was demonstrated at $77 \mathrm{~K}$. The dielectric hysteresis was compared in capacitors with YBCO electrodes and with metal ones. It was shown that the boundary phenomena at the interface of the epitaxially grown layers differ from that in the ferroelectric / metal structures and the hysteresis effect diminishes significantly.

ACKNOWLEDGEMENT. This work was partially supported by the Commission of EU, grant CIPA94 - 0193, as well as by the Bulgarian National Science Foundation, grant no. 526.

\section{REFERENCES}

[1] J.F.Scott and C.A.Paz de Araujo, Science 246 (1989) 1400-1405.

[2] A.T.Findikoglu, Q.X.Jia, I.H.Cambel, X.D.Wu, D.Reador, C.B.Mombourquette, D.McMurry, Appl.Phys.Lett. 66 (1995) 3674-3676.

[3] K.G.Grigorov, G.I.Grigorov, M.Stoyanova, R.Chakalov, J.-L.Vignes, J.-P.Langeron, P.Denjean, J.Perriere, Vacuum, 44, 11/12 (1993), 1119.

[4] A.Benchocine, D.Bouchier, K.G.Grigorov, Materiaux Piezo-Pyro-Ferroelectriques et leurs applications, 3H, 8 et 9 Juin 1993 Limoges, France

[5] J.P.Biersack and L.G.Haggmark, Nucl.Instrum.Meth., 174 (1980), 257

[6] A.Benchocine, Thèse, Univ Paris-Sud, Orsay, (1994), 117.

[7] O.G.Vendik, L.T.Ter-Martirosyan, A.I.Dedyk, S.F.Karmanenko, R.A.Chakalov, Ferroelectrics 144 (1993) 33-44.

[8] A.I.Dedyk, N.W.Plotkina, L.T.Ter-Martirosyan, Ferroelectrics 144 (1993) 77-81.

[9] Karmanenko, M.V.Belousov, R.A.Chakalov, V.Yu.Davydov, A.I.Dedyk, Yu.V.Likholetov, K.F.Njakshev, M.V.Pavlovskaya, L.T.Ter-Martirosyan, Supercond Sci.Technol. 7 (1994) 727-733

[10] O.G.Vendik, L.S.Il'inski, A.D.Smirnov, G.S.Khizha, Sov.Phys.Tech.Phys. 29 (1984).455-458. 